\title{
Potential for Green Hydrogen Production from Biomass, Solar and Wind in Togo
}

\author{
Mawunyo Simon Pierre Kitegi1 ${ }^{10}$, Yendoube Lare², Ousmane Coulibaly³ \\ ${ }^{1}$ WASCAL Alumni, School of Informatics for Climate Change, Ouagadougou, Burkina Faso \\ ${ }^{2}$ Solar Energy Laboratory, Physics Department, Université de Lomé, Lomé, Togo \\ ${ }^{3}$ Laboratory of Physics and Environment Chemistry, School of Informatics for Climate Change, Université Joseph Ki-Zerbo, \\ Ouagadougou, Burkina Faso \\ Email: kitegi.m@edu.wascal.org, yenlare@univ-lome.tg, coulous2005@yahoo.fr
}

How to cite this paper: Kitegi, M.S.P., Lare, Y. and Coulibaly, O. (2022) Potential for Green Hydrogen Production from Biomass, Solar and Wind in Togo. Smart Grid and Renewable Energy, 13, 17-27. https://doi.org/10.4236/sgre.2022.132002

Received: December 28, 2021

Accepted: February 6, 2022

Published: February 9, 2022

\section{Copyright (c) 2022 by author(s) and} Scientific Research Publishing Inc. This work is licensed under the Creative Commons Attribution International License (CC BY 4.0).

http://creativecommons.org/licenses/by/4.0/

(c) (i) Open Access

\begin{abstract}
Potential of green hydrogen producing from biomass, solar and wind in Togo has been performed. The availability of these three resources has been depicted with maps showing them per cantons in Togo, thus, by using the datasets from ESA Biomass Climate Change Initiative, the global solar atlas and the global wind atlas. The conversions rates used were: for solar resource, $3 \%$ of land was allocated for the analysis after removing the exclusions with a conversion rate of $52.5 \mathrm{kWh} / \mathrm{kg}$ of hydrogen; for biomass hydrogen, the conversion rate of $13.4 \mathrm{~kg} \mathrm{BS} / \mathrm{kg} \mathrm{H}_{2}$ was assumed. Wind resources at $50 \mathrm{~m}$ above ground were not sufficient to evaluate the potential as it is lower than class 3 winds. QGIS version 3.6.4 and $\mathrm{R}$ version 4.0.4 were used. Results showed that biomass is the leading resource for producing green hydrogen from renewable energy resources; with good impact in these two cantons: Bassar, Gobe/ Eketo/Gbadi N'Kugna. However, this resource is still decreasing and in some cantons it is null.
\end{abstract}

\section{Keywords}

Green Hydrogen Potential, Solar, Wind, Biomass, Climate Change

\section{Introduction}

The United Nations have made projections on the world population to 2030, 2050 and 2100 [1]. According to findings, the world population is still increasing, even if some countries are experiencing a decrease. Besides, Sub-Saharan Africa will account for most of the growth of the world's population over the coming decades, while several other regions will begin to experience decreasing 
population numbers. In Togo, Nyoni et al. [2] have made a projection based on 1960 to 2017 population data in Togo and they found that Togo's population can reach 14.2 million in 2050. This growing population will certainly insinuate the increase of needs. Among these needs, energy is one of the essentials. The Togolese Agency for Rural Electrification and Renewable Energies [3] has stated that the rate of electricity access was around $45 \%$ in 2018 and $8 \%$ in rural areas. Compare to the previous population estimated data, we can conclude that there is an urgent need to find sustainable and climate smart ways of generating energy for the growing population. The seventh sustainable development goals were built to ensure access to affordable, reliable and modern energy for all by 2030 . Vijay [4] explores how green energy is useful for the future aspect of the world. She found that sources of green energy such as solar, wind, geothermal and hydro energy, developed and promoted as alternative source will make a little or no contribution to climate change. Most known form of renewable energy comes from solar energy. Anyone can install, where sunlight is available, in its space's solar panels. Other areas where wind is plenty can be full of wind turbines to produce wind energy. To the previous, we can add the marine energy which is also an important renewable energy resource. Biomass is another source of renewable energy. It can be used as a transportation fuel and to produce electricity. There is a problem of energy storage when it comes in the using of renewable energies. How to maximize the storage of the energy? To solve it, the conversion of renewable energy electricity to hydrogen became the best way. So many researchers have worked on the subject. The primitive designation of green hydrogen was renewable hydrogen. It was used for the first time in 1995 by the Hydrogen Technical Advisory Panel (HTAP) of the US Department of Energy's (DOE) as hydrogen produced from renewable energies. Furthermore, in 2020 IRENA has distinguished 4 different shades of hydrogen [5]: the grey hydrogen, the blue, the turquoise hydrogen and finally, the green hydrogen. In 1992, Veziroglu and Barbir [6] had compared conventional and unconventional fuels with the green hydrogen through these criteria: transportation fuel, versatility, utilization efficiency, environmental compatibility, safety and Economics (effective cost). At the end of the study, green hydrogen was selected as the best transportation fuel, the most versatile fuel, the most efficient fuel, the environmentally most compatible fuel, the safest fuel, and the most cost-effective fuel to society and the paper was named the Hydrogen, the wonder fuel. In 2008, Veziroglu and Sumer [7] has confirmed the previous result and they had named it green hydrogen, the 21 st century fuel. But to make further studies on the implementation of green hydrogen technology, it is important to know the potential for green hydrogen of the area. The United States have assessed their potential in 2007 [8], Argentina in 2014 [9] from their key renewable resources. These studies have helped them to visualize the potential in any cantons of the country and enable other researches and investments to establish green hydrogen economy in these countries at the appropriate areas. To date, there is no study to know the potential of 
green hydrogen production from renewable energy resources in Togo. This paper intends to fill this void for Togo, by assessing the potential for green hydrogen production from wind, solar and biomass. This paper intends to pull out the potential for green hydrogen production in Togo.

\section{Materials and Methods}

\subsection{Presentation of TOGO, the Study Area}

Togo depicted in Figure 1, is located in West Africa, covering 57,000 square kilometers, with a population of approximately 8 million. It has 5 different economic regions. They are: "region des savanes", "regions de la kara", "regions centrale", "region des plateaux" and "region maritime".

\subsection{Datasets}

\subsubsection{Biomass Datasets}

The dataset used is from the ESA Biomass Climate Change Initiative [10]. The data consist of the forest above ground biomass for the year 2018. It was obtained from a grouping of Earth observation data, the Copernicus Sentinel-1 mission, Envisat's ASAR instrument and JAXA's Advanced Land Observing Satellite (ALOS-1 and ALOS-2), along with additional information from Earth observation sources. It is expressed in Megagram per hectare. They have defined the above ground biomass as the mass of the oven-dry weight of the woody parts such as stem, bark, branches and twig of all living trees excluding stums and roots.

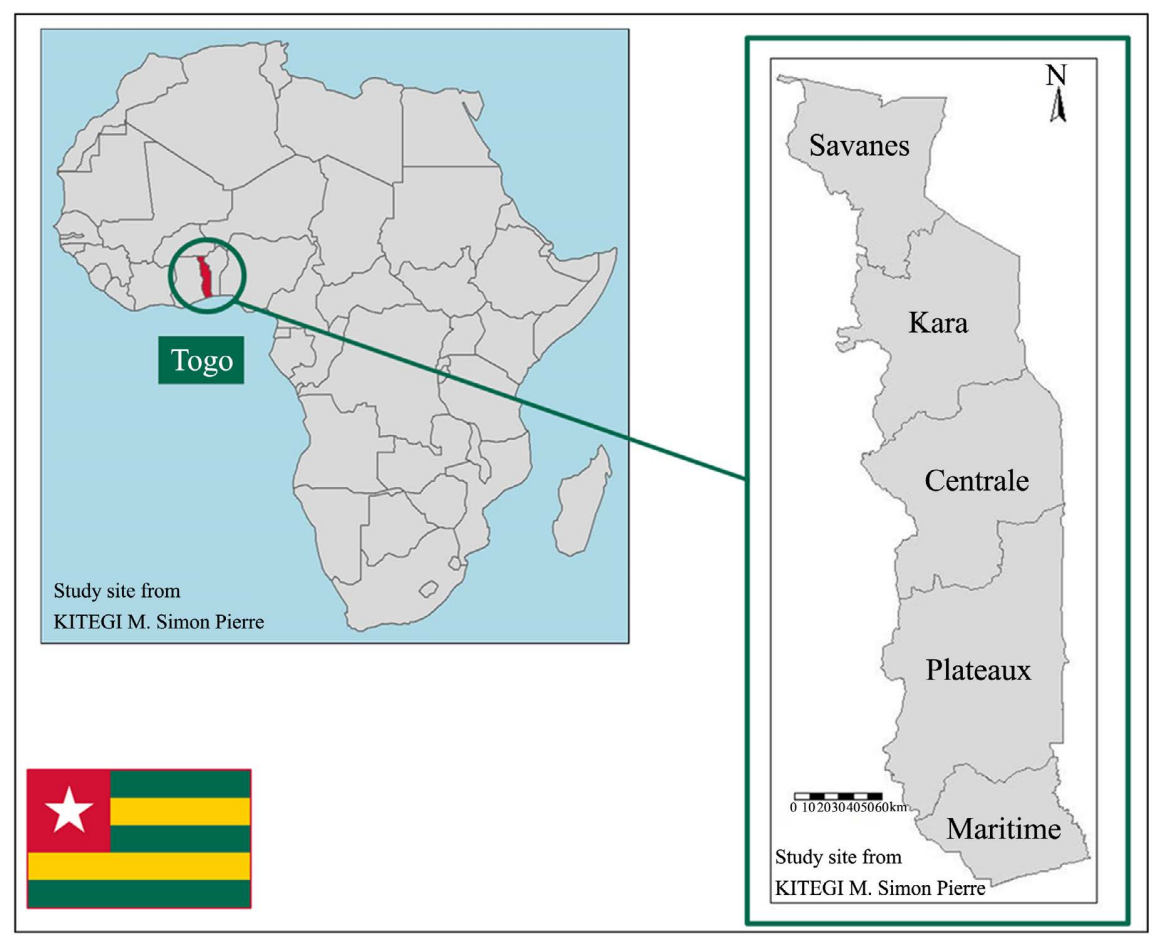

Figure 1. Presentation of Togo, the study area. 


\subsubsection{Solar Datasets}

The datasets consist of long-term yearly average of global horizontal irradiation (GHI) in $\mathrm{kWh} / \mathrm{m}^{2} /$ day. This data layer represents an output from the Solaris global solar model. It has been delivered for the Global Solar Atlas [11], an online platform funded by the Energy Sector Management Assistance Program (ESMAP), a multi-donor trust fund administered by The World Bank, under a global initiative on Renewable Energy Resource Mapping covering the period 1994-2018. The software R version 4.0.4 was used for the analysis.

The exclusions are land used where solar projects cannot be installed. The data [12] consists of National Park (4), Forest Reserve (65), Faunal Reserve (4), Community Forest (3), Natural resource management area (4), Habitat and species management reserve (1), UNESCO-MAB Biosphere Reserve (2), Ramsar Site, Wetland of International Importance (4) added to inlands water areas.

\subsubsection{Wind Datasets}

For the assessment, we used the global wind atlas data [13]. It has been developed through the partnership of the Department of Wind Energy at the Technical University of Denmark and the World Bank Group. The purpose of this dataset is to support wind power development during the exploration and preliminary wind resource assessment phases before the installation of meteorology measurement stations on site. The data downloaded is from $50 \mathrm{~m}$ above ground as done by Mann and Milbrandt [8] and Sigal [9].

\subsection{Analysis Methodology}

\subsubsection{Analysis Methodology for Potential of Green Hydrogen Production Assessment from Biomass}

To estimate the green hydrogen potential from biomass, as we do not have the conversion rate of our local biomass to green hydrogen, we used the conversion rate used in the same past study in USA [8], a conversion rate of $13.8 \mathrm{~kg}$ bone dry weight $(\mathrm{BDW}) / \mathrm{kg}$ hydrogen was applied. This rate is based on the conversion of lignocellulosic plant material to hydrogen via gasification analyzed by the US Department of Energy's Hydrogen Analysis (H2A) Group. In Argentina, to calculate the potential for hydrogen production [9] per unit area from the dry biomass supply available, a conversion rate of $13 \mathrm{~kg}$ Biomass Supply/kg H2 was assumed. This value is based on the conversion rate of lignocellulosic plant material to hydrogen via gasification. Our data is about all the above-ground biomass available, so we chose to apply the mean of these two values, $13.4 \mathrm{BS} / \mathrm{kg} \mathrm{H} 2$ to estimate the potential in Togo. QGIS version 3.6.04 was used added to $\mathrm{R}$ version 4.0.4, for the analysis.

\subsubsection{Analysis Methodology for Potential of Green Hydrogen Production Assessment from Solar}

The evaluation of the potential of solar hydrogen from the solar resources depicted in Figure 4 used the electrolysis conversion rate with the same efficiency as that considered in the past studies in Argentina [9]; that is, $52.5 \mathrm{kWh} / \mathrm{kg}$ of 
hydrogen. We consider also the same photovoltaic panels of $222 \mathrm{~W}$ rated power, with a surface of $1.63 \mathrm{~m}^{2}$ and an efficiency of $13.6 \%$. We took into account that the effective area for panels could be $3 \%$ of the total land suitable for solar ventures. The disproportion of our population with the high numbers in urban than rural areas, the decentralization plans and the growing population suggest that the $3 \%$ per canton can be suitable for this analysis. This value is somewhat lower than the $4.5 \%$ assumed by Sigal in Argentina [9] due to the lowness of the population density of Argentina than USA who used 3\%.

\subsubsection{Analysis Methodology for Wind Potential at $50 \mathrm{~m}$ above Ground} The dataset has been processed in order to get the wind potential in the country.

\section{Results and Discussion}

\subsection{Biomass Available and Potential of Green Hydrogen from It in Togo}

The processing of the biomass resources data per cantons in Togo helps to roll out the map of the available biomass in Togo depicted in Figure 2.

The available biomass resources are concentrated in the "region centrale" and "region des plateaux". Most of cantons in these regions have over than millions of kilograms of biomass per hectare (Figure 2). This leads to the green hydrogen potential map illustrated on Figure 3, as the green hydrogen presence is related directly, without any restriction, to the biomass available.

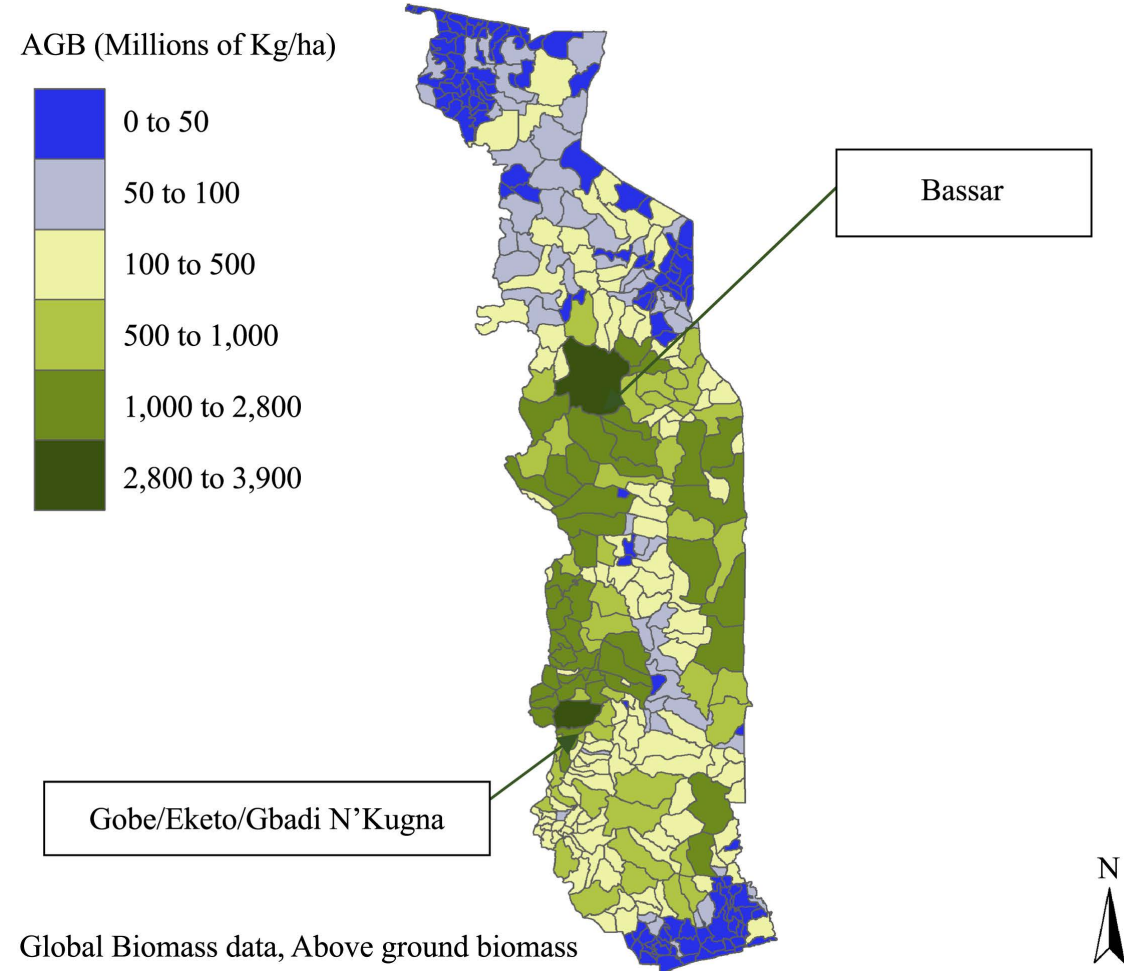

Figure 2. Available biomass (Above-Ground Biomass) in Togo in millions of kilogram per hectare. 


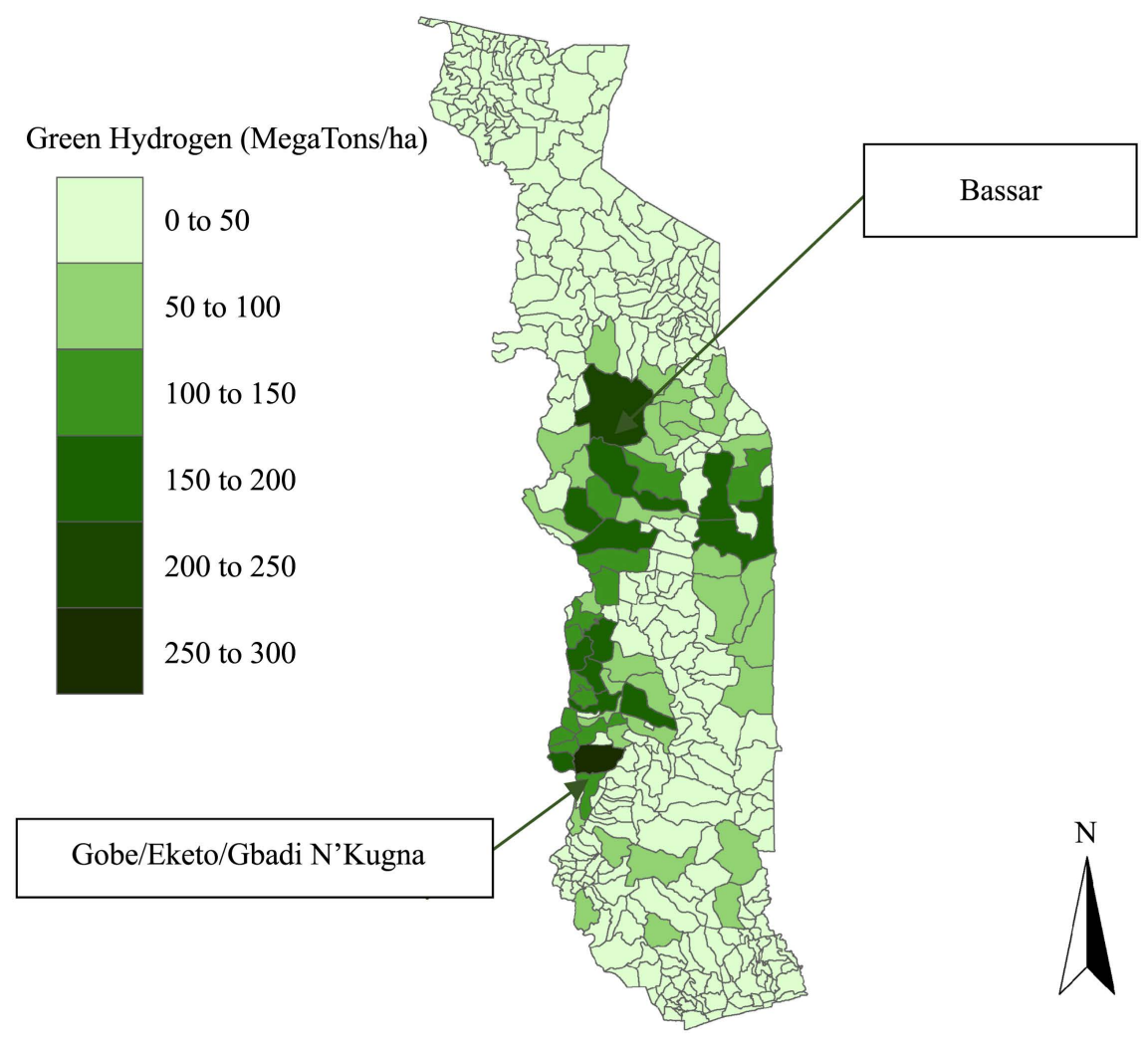

Figure 3. Green hydrogen potential from biomass in Togo, in megatons per hectare.

Figure 3 shows that Bassar, Gobe/Eketo/Gbadi N'Kugna are the cantons with the highest potential of green hydrogen production from biomass. They can produce respectively 2975.732 and 3896.426 million of kilogram per hectare. The second highest cantons account are Alibi, Aouda, Atchintse, Badou, Boulohou, Diguengue, Djon, Elavagnon/Atigba, Fazao, Gbende, Kaboli, Kessibo, Klabe Efoukpa, Koussountou, Kpete Bena, Lama-Tessi, M’Poti, Otadi, Seregbene, Sotouboua. Tchebebe, Tintchro, Tomegbe, Yalla, Yegue. They can produce between 1000 and 2800 millions of kilograms per hectare. The results of this analysis show clearly that Togo has a potential to produce green hydrogen from biomass gasification.

\subsection{Solar Resource and Green Hydrogen Potential from It in Togo}

The processing of the solar resources data per cantons in Togo help to roll out the map of the available solar resource in Togo depicted in Figure 4.

Figure 5 depicts the green hydrogen potential from solar in Togo. The "region des savanes" and "region de la kara" would be the best producers as they can produce over 155 tons hydrogen per kilometer square. It would be good to start green hydrogen solar projects pilots in these regions, particularly in "region des savanes". The development of pilots demonstration projects in these two regions could be based on the same process as done in other countries for instance in Pakistan [14] and Germany [15] where these facilities were used. The Photovoltaic farm to gather the sun energy, the electrolyser for helping to split water into 
Solar resource $\mathrm{kWh} / \mathrm{m}^{2} /$ day
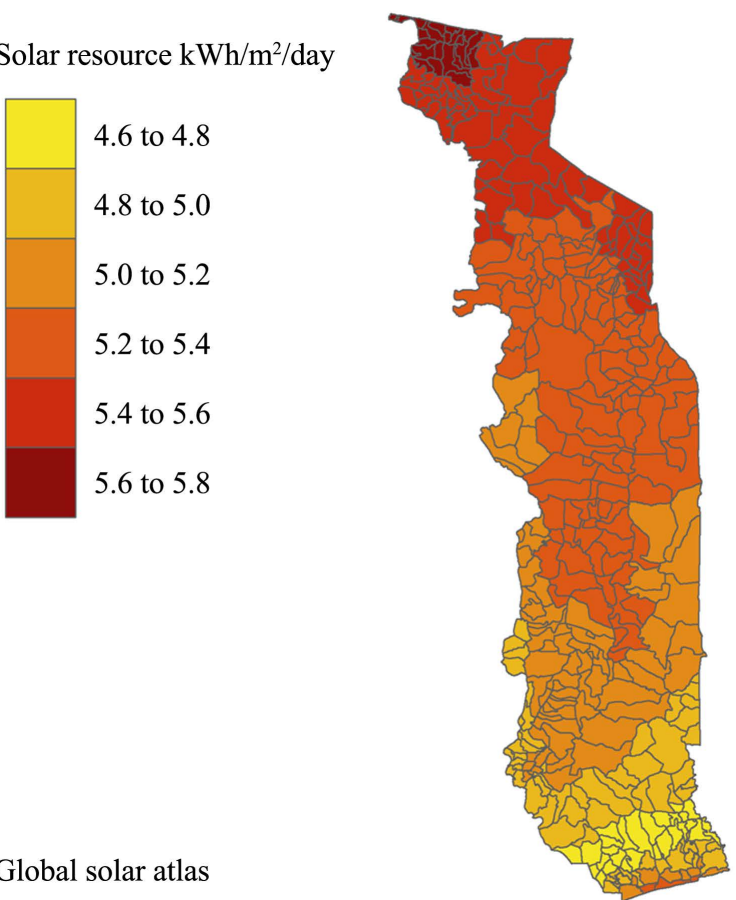

Global solar atlas

Figure 4. Available Solar resource in Togo in kilowatt hour per meter square per day.

Green hydrogen Tons $/ \mathrm{km}^{2} /$ year

\begin{tabular}{|l|l|}
\hline 130 to 135 \\
135 to 140 \\
140 to 145 \\
145 to 150 \\
150 to 155 \\
155 to 160 \\
160 to 165
\end{tabular}

Global solar atlas
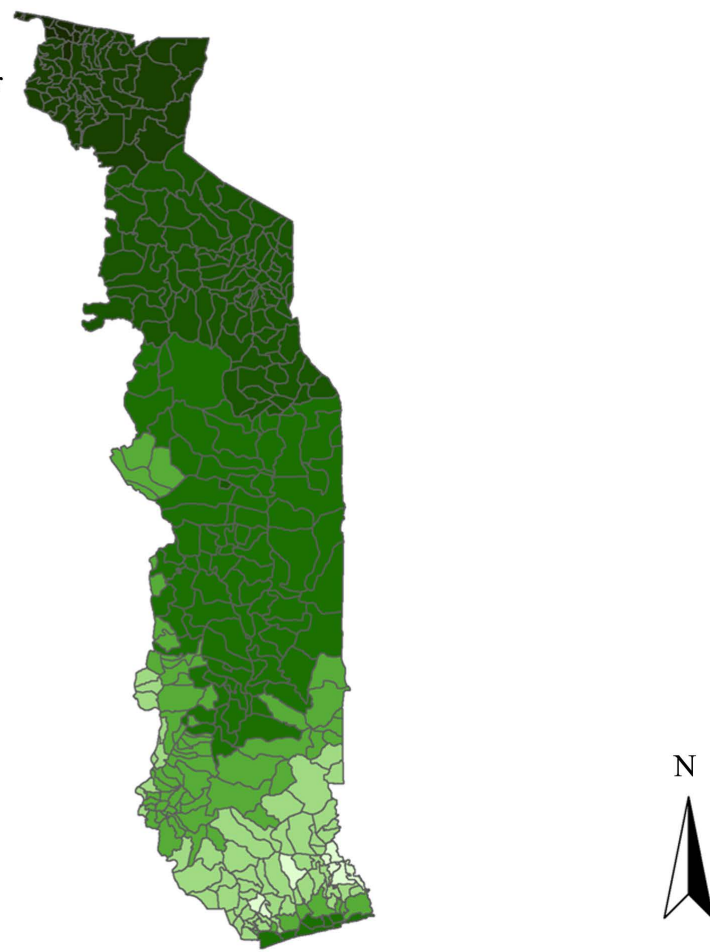

Figure 5. Green hydrogen potential from solar in Togo in tons per kilometer square per year.

hydrogen and oxygen, using the electricity produced by the photovoltaic cells, the compression and storage tools to store the hydrogen produced, the desalination plant to help producing fresh water to feed the electrolyser, the gas filling 
unit, the power unit and data acquisition and storage unit. The project could start for few regions and being promoted and developed in the whole country. This could help to assure the energy independence in the cantons, create jobs, force decentralization, help to manage public water storage for a good purpose and limit the propagation of malaria.

\subsection{Wind Resource in Togo}

The highest wind speed at 50 meters above ground is $5 \mathrm{~m} / \mathrm{s}$ in Togo (Figure 6). It is lower than the one considered by Mann and Milbrandt [8] and Sigal [9]. They have all made the analysis with wind power class 3 which is between 6.4 to $7.0 \mathrm{~m} / \mathrm{s}$. So, the analysis of green hydrogen from wind cannot be done in Togo as the wind power is low.

This result shows that we could not produce green hydrogen from wind in Togo as the highest speed is lower than wind power class 3 classification which is between 6.4 to $7.0 \mathrm{~m} / \mathrm{s}$ [14]. For the moment, we do not have available measured wind speed above $30 \mathrm{~m}$ and above $50 \mathrm{~m}$ in Togo. The data used is a raster dataset due to the lack of in situ data.

\subsection{Total Amount of Green Hydrogen Potential from Biomass and Solar in Togo}

To compute the total potential for green hydrogen from biomass and solar, we compute the sum of the potentials from biomass and solar.

The total amount of hydrogen that could be produced from renewable energy resources (biomass and solar) by canton in Togo is depicted in Figure 7. The

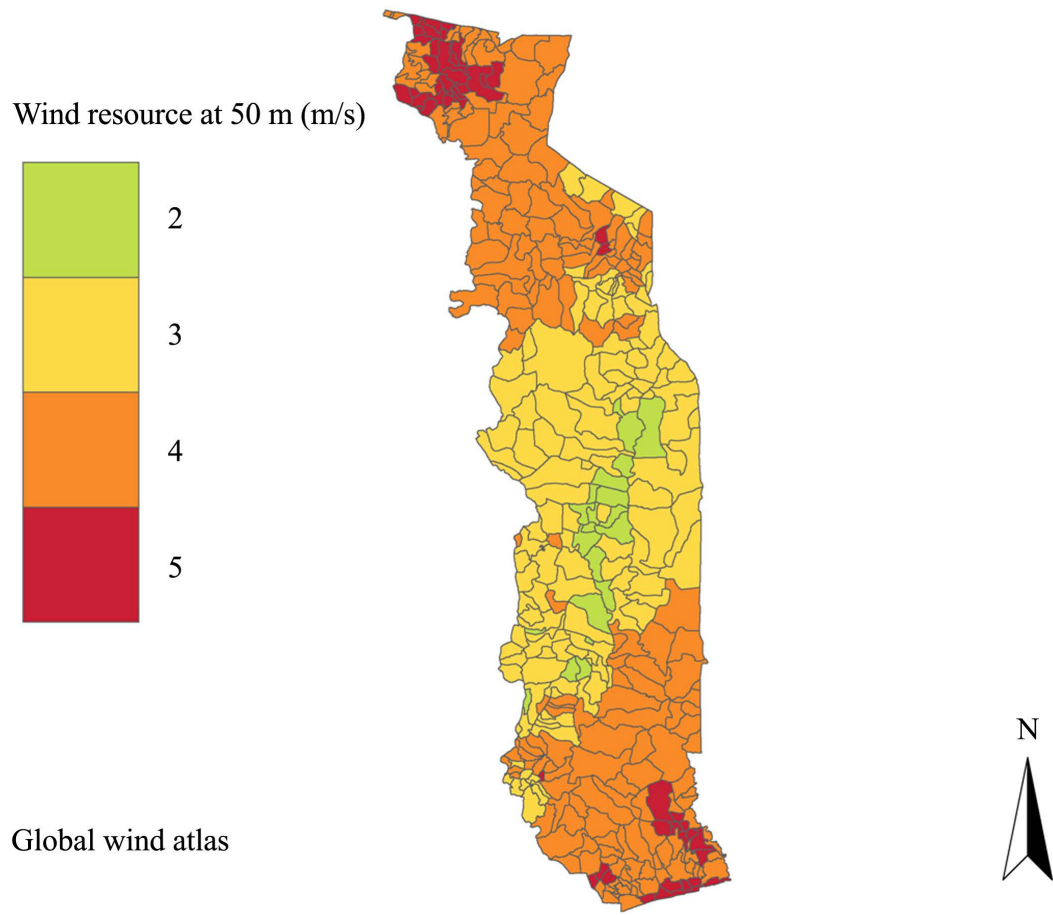

Figure 6. Available wind speed at $50 \mathrm{~m}$ above ground in Togo. 

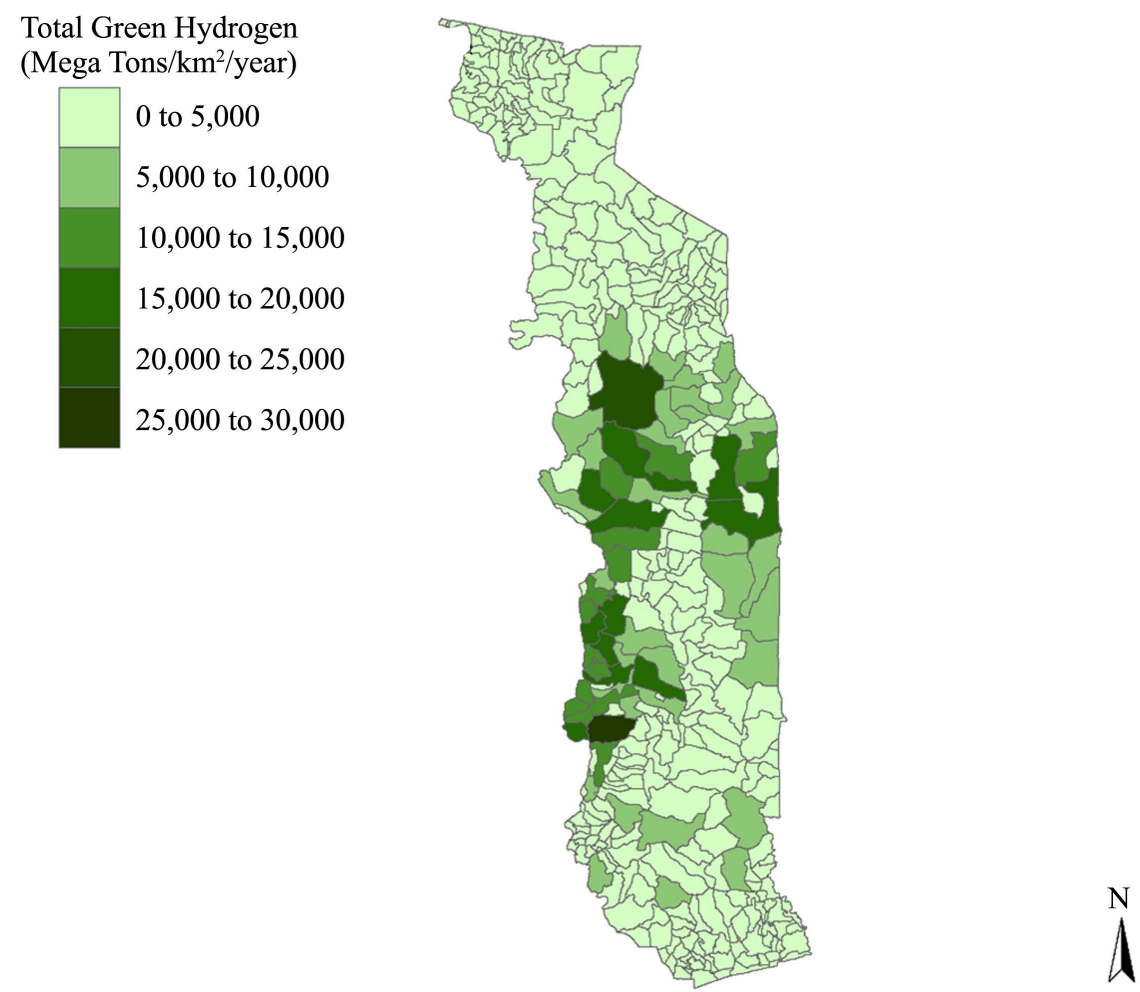

Figure 7. Total green hydrogen producible per cantons in Togo.

potential from biomass being largely dominant compared to that of solar, the map is quietly as same as the map of green hydrogen producing from biomass. The same cantons with the best biomass potential show the top global potentials. From this, we can say that biomass is the highest resource to produce green hydrogen in Togo. But the concentration of this resource is in "region centrale" and "region des plateaux". These are parts of Togo where the pilots' projects can start. The other parts of the country need reforestation projects.

The results show that biomass is the highest resource for producing green hydrogen in Togo. This is similar to the report of West African Economic and Monetary Union [16] on available energy resources in Togo. The report stated the flowing situations:

"The energy sector is dominated by biomass which represent $100 \%$ of the national energy balance in 2018 "

Togo is consuming biomass highly than other sources of energy but is producing less biomass.

This is drawing a problem at the horizon where human is using the natural resources but is producing it less [16]. It could be good to start the process of the conversion of biomass in green hydrogen to meet the energy need of the population with a good plan of reforestation. The biomass gasification project will force the production of biomass and reduce its consumption. This will help to limit the consumption of biomass and limit also the contribution of energy sector to climate change by finding a clean source of energy to the public and an independence of energy to the local region. This require the education to the popula- 
tion on the use of new source of energy, for human behavior is difficult to change. Then, our countries should work for the development of energy policy to facilitate the development of green hydrogen in local areas, the development of a favorite economic environment for innovations for smart green hydrogen energy grids.

\section{Conclusions}

For the first time in Africa, precisely in Togo, an analysis of the potential for green hydrogen producing from biomass, solar and wind has been performed. Green hydrogen can be produced in Togo from Biomass and solar. The study has shown that biomass is the leading resource. Togo can produce a maximum of 100,000 Megatons of green hydrogen from solar and biomass. Biomass is currently used in the country but for other purpose which is contributing to climate change. Green hydrogen transition would be good for reinforcing the decentralization process, the reforestation in places where the biomass is decreasing, the adaptation to climate change and to meet the growing demand of energy in the population. Some other relevant aspects could be investigated, in complement of this present research:

- Climate change impact on biomass in Togo;

- Climate change impact on Solar and Wind in Togo;

- Energy consumption per cantons in Togo for further comparison;

- Policy on the developing of green hydrogen economy in Togo;

- Investment opportunity per cantons where the potential of producing green hydrogen is the best;

- Willingness of the population to change its behavior by using directly the green hydrogen than the biomass as source of energy;

- Amount of biomass available in each canton to produce green hydrogen;

- Conversion rate of local biomass to green hydrogen

- Amount of biomass that can be really used for green hydrogen production

\section{Acknowledgements}

We are grateful to WASCAL (The West African Service Centre on Climate Change and land Use) which fund this project. Besides, express our gratitude to the "Université de Ouagadougou" and the "Université de Lomé" who hosted us respectively during the training and the project development.

\section{Conflicts of Interest}

The authors declare that they have no known competing financial interests or personal relationships that could have appeared to influence the work reported in this paper.

\section{References}

[1] United Nations, Department of Economic and Social Affairs, and Population Divi- 
sion (2019) World Population Prospects 2019: Highlights. United Nations, Geneva.

[2] Nyoni, T. (2019, May) Prediction of Total Population in Togo Using ARIMA Models Prediction of Total Popualtion in Togo Using Arima Models. Munich Personal RePEc Archive.

[3] Lighting Global (2021) Togo Electrification Strategy. https://www.lightingglobal.org/wp-content/uploads/2018/12/Togo-Electrification-S trategy-Short-EN-Final.pdf

[4] Kalyani, V., Dudy, M. and Pareek, S. (2015) Green Energy: The Need of the World. Journal of Management Engineering and Information Technology, 2, 2394-8124.

[5] International Renewable Energy Agency (2020) Renewable Energy Statistics 2020. International Renewable Energy Agency, Abu Dhabi, 408.

[6] Vezirolu, T. and Barbir, F. (1992) Hydrogen: The Wonder Fuel. International Journal of Hydrogen Energy, 17, 391-404. https://doi.org/10.1016/0360-3199(92)90183-W

[7] Nejat Veziroglu, T. (2009) 21st Century's Energy: Hydrogen Energy System. In: Sheffield, J.W. and Sheffield, Ç., Eds., Energy Conversion and Management, 49, 9-31. https://doi.org/10.1007/978-1-4020-6442-5 2

[8] Milbrandt, A. and Mann, M. (2007) Potential for Hydrogen Production from Key Renewable Resources in the United States. National Renewable Energy Laboratory, Golden. https://doi.org/10.2172/899141

[9] Sigal, A., Leiva, E. and Rodríguez, C.R. (2014) Assessment of the Potential for Hydrogen Production from Renewable Resources in Argentina. International Journal of Hydrogen Energy, 39, 8204-8214. https://doi.org/10.1016/j.ijhydene.2014.03.157

[10] Santoro, M. and Cartus, O. (2021) ESA Biomass Climate Change Initiative (Biomass_cci): Global Datasets of Forest Above-Ground Biomass for the Years 2010, 2017 and 2018, v2. Centre for Environmental Data Analysis (CEDA), Oxfordshire.

[11] Global Solar Atlas (n.d.). https://globalsolaratlas.info/download/togo

[12] Protected Planet (n.d.) Togo. https://www.protectedplanet.net/country/TGO

[13] Global Wind Atlas. https://globalwindatlas.info

[14] Lutfi, N. and Veziroglu, T. (1992) Solar-Hydrogen Demonstration Project for Pakistan. International Journal of Hydrogen Energy, 17, 339-344.

https://doi.org/10.1016/0360-3199(92)90170-2

[15] Szyszka, A. (1998) Ten Years of Solar Hydrogen Demonstration Project at Neunburg Vorm Wald, Germany. International Journal of Hydrogen Energy, 23, 849-860. https://doi.org/10.1016/S0360-3199(97)00172-9

[16] Chitou, S.M. and Gbandey, G.T. (2020) Atlas de l'énergie dans l'espace UEMOARapport 2020. L'Institut de la Francophonie pour le développement durable (IFDD), Québec, 156. 